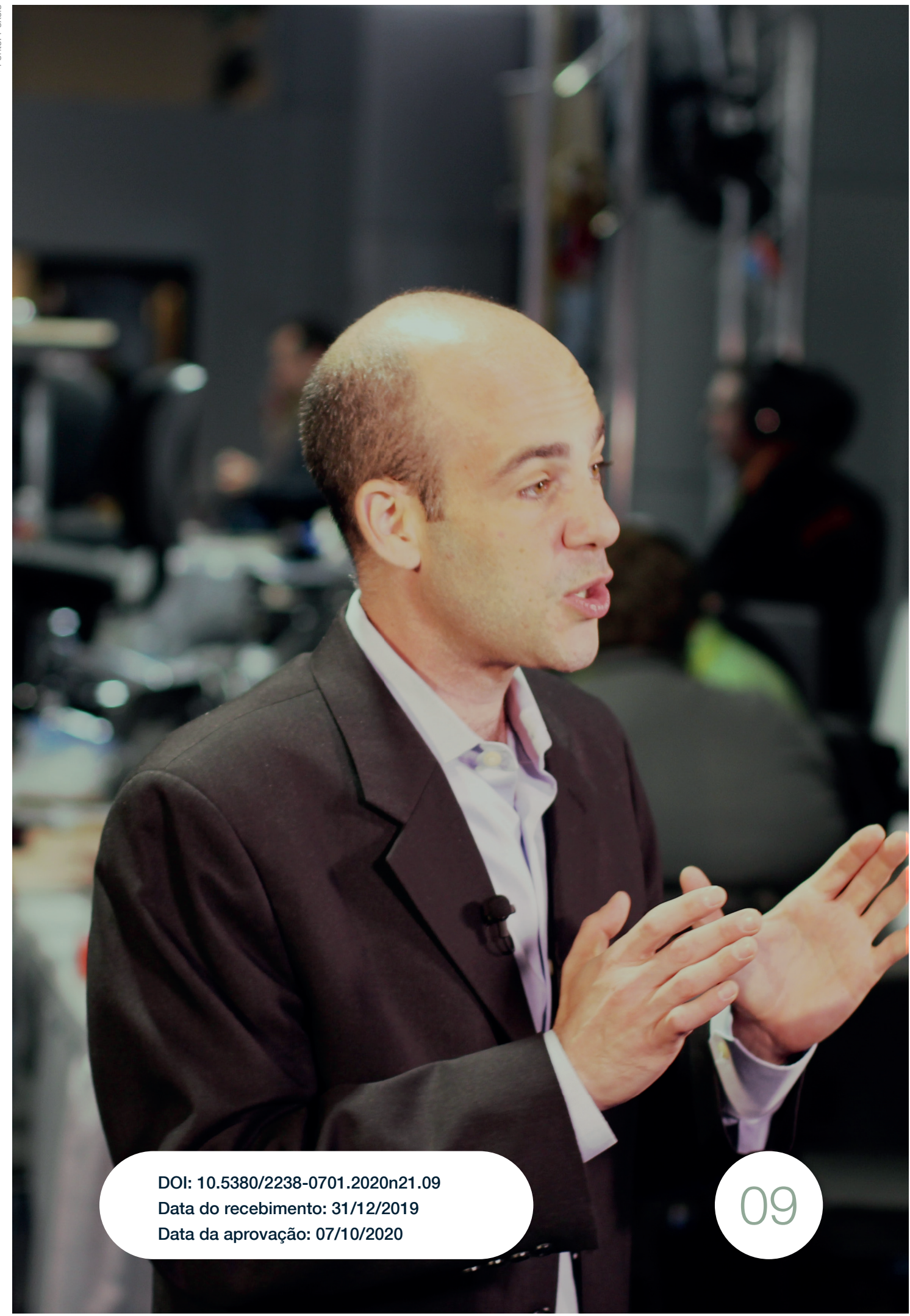


Quando dilemas viram rotinas: desafios éticos na produção de noticiários criminais 


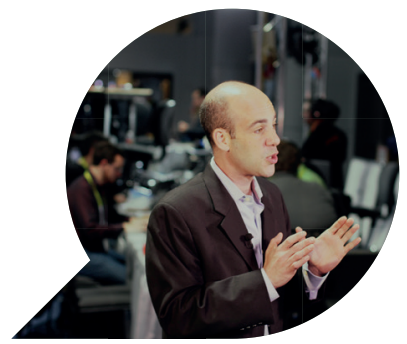

\title{
Quando dilemas viram rotinas: desafios éticos na produção de noticiários criminais
}

\author{
When dilemmas Become Routines: Ethical Challenges \\ in Criminal News Production
}

\section{Cuando los dilemas se convierten en rutinas: desafíos éticos en la producción de noticias criminales}

\section{HENDRYO ANDRÉ 1}

Resumo: Com o objetivo de avaliar como dilemas éticos que envolvem a cobertura da violência são naturalizados pelos jornalistas, no presente estudo discute-se o cenário de responsabilidade profissional em relação às implicações das práticas sensacionalistas no processo de midiatização. A partir de entrevistas semiestruturadas com cinco repórteres com ampla experiência televisiva e que trabalham nos noticiários criminais Balanço Geral e Tribuna da Massa, veiculados em Curitiba (PR), os resultados apontam para a necessidade de entender as potencialidades dessas narrativas para além de um recurso meramente econômico.

Palavras-chave: Telejornalismo; Crime; Ética; Narrativa jornalística; Rotinas produtivas. 
Abstract: In order to assess how journalists naturalize ethical dilemmas involving coverage of violence, this research discusses the scenario of professional responsibility in relation to the implications of sensationalist practices in the mediatization process. Based on semi-structured interviews with five extensive television experience reporters who work on the criminal newscasts Balanço Geral and Tribuna da Massa, programs broadcasted in Curitiba $(\mathrm{PR})$, the results indicate to the need to understand the potential of these narratives beyond a economic resource.

Keywords: Television Journalism; Crime; Ethic; Journalistic narrative; Production routines.

Resumen: Al evaluar cómo los dilemas éticos que enredan la cobertura de la violencia son naturalizados por los periodistas, este estudio discute el escenario de responsabilidad profesional en relación a las implicaciones de las prácticas sensacionalistas en el proceso de mediatización. Desde entrevistas semiestructuradas con cinco reporteros con amplia experiencia televisiva que trabajan en los noticieros criminales Balanço Geral y Tribuna da Massa, emitidos en Curitiba (PR), los resultados indican la necesidad de comprender el potencial de estas narrativas más allá de un mero recurso económico.

Palabras clave: Teleperiodismo; Crimen; Ética; Narrativa periodística; Rutinas productivas.

\section{Introdução}

Com abrangência nacional e regional, os noticiários criminais se popularizam na TV brasileira por estabelecerem como diferencial a presença de um âncora que comenta as notícias, somada à exibição de reportagens que, a partir de recursos dramáticos, narram a tragédia social cotidiana que produz anualmente mais de 60 mil homicídios no país (BRASIL, 2018). Esses produtos informativos costumam ser associados, por vezes com carência de crítica, a violações de direitos fundamentais. Entre as mais comuns estão o desrespeito à presunção de inocência e 
à exposição de vítimas, agressores e familiares de forma indevida, bem como a incitação a crimes, desobediência a leis ou decisões judiciárias e, enfim, a formulação de discursos de ódio contra determinados grupos sociais (VARJÃO, 2015).

Essas acusações não impediram que o gênero ganhasse proeminência em, no mínimo, duas fases. Na reabertura política, com a fundação do SBT (1981), houve a criação de atrações popularescas e a retomada de outras banidas da televisão nos anos 1960. Já na década de 1990, sobretudo após a implantação do Plano Real, com o aumento nas vendas de aparelhos ocorreu a individualização do ato de ver televisão entre a classe média e o acesso ao bem de consumo pelas camadas mais pobres (ROXO, 2010). A segunda fase marcou ainda a ampliação de investimentos das emissoras em telejornalismo, inclusive em âmbito regional (BECKER, 2010). O gênero, já no início do século, adotou como regra a regionalização padronizada (HAMILTON, 2008), uma estratégia que carrega propostas editoriais de abrangência nacional, mas com uma roupagem local, algo que explica parte do sucesso editorial desses produtos na nova ecologia audiovisual.

Devido ao contraste entre popularidade e questionamentos sobre direitos violados, esses informativos precisam cada vez mais ser objeto do campo da ética. Nesse contexto, o diálogo com profissionais que trabalham com crimes pode desmistificar o princípio de que a mera cobertura da violência seja algo antiético, bem como compreender a naturalização dos dilemas vividos por esses atores sociais. Em meio à rotina produtiva, jornalistas comportam-se de forma prática-moral (SÁNCHEZ-VÁZQUEZ, 1987), isto é, tomam decisões a partir de problemas empíricos, levando em consideração as consequências imediatas e objetivas de suas ações frente a si próprios, a seus pares e, claro, ao público. A vinculação do programa a uma figura pública, a hesitação sobre invasão de privacidade a partir de imagens flagradas por uma câmera de segurança ou de uma entrevista, ou ainda, a publicação de uma denúncia que envolva corrupção policial são exemplos de decisões corriqueiras que uma equipe de produção enfrenta.

Ao partir do pressuposto de que é possível estruturar um objeto de estudo científico por uma dimensão ética, neste estudo visa-se, a partir de entrevistas com cinco jornalistas que trabalham nos dois principais noticiários criminais exibidos em Curitiba (PR), Balanço Geral Curitiba 
(RICTV/Record) e Tribuna da Massa (Rede Massa/SBT), problematizar, em confrontação com o viés deontológico e normativo, como a cobertura de crimes é naturalizada por ações prático-morais tomadas por jornalistas frente a problemas empíricos.

Para atingir o objetivo, versa-se sobre o cenário de responsabilidade do jornalista no que se refere às implicações das práticas sensacionalistas nas produções de sentidos. Os resultados mostram a necessidade de entender as potencialidades dessas narrativas para além de um recurso meramente econômico, aspecto que, embora pouco compreendido pelos jornalistas, auxilia na explicação dos motivos pelos quais esse nicho jornalístico cresce em credibilidade junto à audiência, conforme identificado na pesquisa que originou este texto (ANDRÉ, 2018).

\section{Notícias sobre crimes e exterioridade na responsabilidade do jornalista}

As notícias criminais detêm uma lógica distinta da empregada nos fait divers, produtos efêmeros tidos como extraordinários e narrados por uma angulação eminentemente ligada ao melodrama e/ou ao entretenimento. Essa diferenciação que reforça a separação entre fait divers e sensacionalismo (ANGRIMANI, 1995) abre campo à compreensão das implicações do último nas práticas cotidianas e nas produções de sentidos. Martín-Barbero e Rey (2001, p. 26) avaliam a TV como um "sofisticado dispositivo de moldagem e deformação do cotidiano e dos gostos populares e uma das mediações históricas mais expressivas de matrizes narrativas, gestuais e cenográficas do mundo cultural popular". Martín-Barbero (2015, p. 250), defensor de uma coesão entre a gênese do discurso sensacionalista e a cultura popular, critica a redução do "sensacionalismo a um 'recurso burguês' de manipulação e alienação".

Nessa perspectiva, os fatos veiculados nos noticiários criminais superam a notícia em si, ou seja, constituem "uma rede de múltiplas intertextualidades" (MATHEUS, 2011, p. 16). O resultado desses elos narrativos que produzem sentido à violência está na interdependência na qual as narrativas noticiosas valorizam a noção de alteridade a um inimigo comum, criam um clima de imprevisibilidade concernente à morte do próprio telespectador (ANDRÉ, 2018) e promovem uma percepção de 
fragilidade inerente ao projeto de modernização (ORTIZ, 2001), um fenômeno que no Brasil foi estruturado pela própria televisão.

Esses fatores, claro, permeiam discussões éticas. Para se popularizarem, os noticiários criminais usaram - e não cabe julgamento sobre as intencionalidades - como estratégia discursiva de endereçamento dois valores amarrados ao campo da ética: as noções de justiça, encarada como objetivo específico da ação moral, e de verdade, vista como objetivo da ação intelectual (FREITAG, 1992). Estruturou-se uma moral hegemônica dentro desse dispositivo narrativo, na qual os princípios ideológicos se manifestam "em diversos planos: psicológico, social, prático-utilitário, jurídico, religioso ou estético" (FREITAG, 1992, p. 23).

Para compreender o estatuto das notícias criminais e, com isso, desvinculá-las dos fait divers, é preciso demonstrar que, apesar do aparente caráter simplório e rústico de edição e da linguagem, há uma densa economia estética do sensacionalismo (MATHEUS, 2011). Esse fator permeia os comportamentos práticos-morais dos jornalistas nas rotinas produtivas, inclusive para solucionar dilemas éticos. A noticiabilidade, forma dinâmica de leitura de um acontecimento e de decisão sobre a forma de narrá-lo, permite conhecer e superar desafios práticos e éticos que envolvem o ofício. O conceito agrega qualquer atributo que interfira ou altere o processo de produção, desde especificidades do fato e das referências anteriores do profissional até elementos como "condições favorecedoras ou limitantes da empresa de mídia, qualidade do material (texto ou imagem), relação com as fontes e com o público, fatores éticos e ainda circunstâncias históricas, políticas, econômicas e sociais" (SILVA, 2014, p. 52).

A transformação de dilemas em rotinas é um fator que inibe reflexões sobre as implicações do fazer jornalístico e dificulta que essas consequências sejam compreendidas ou avaliadas. Ligados à realidade objetiva, interferem na rotina produtiva a busca desenfreada por audiência pregada pelos axiomas da indústria cultural, a idealização de um público-alvo matizada nas estratégias de endereçamento das mensagens (OLIVEIRA, 2014) e a própria formação sociocultural da sociedade brasileira com seus históricos índices de desigualdade.

As implicações colocam em contraste duas formas de se pensar e produzir notícias, dois modos que trazem à tona o papel de responsabilidade dos profissionais. Segundo Cornu (1999), há um jornalismo 
de convicção, ligado a crenças e preocupado majoritariamente com a missão de dizer algo, e um jornalismo de responsabilidade, que "relacionaria a informação com as consequências da sua difusão, em particular com as suas repercussões sobre a vida física e a integridade moral das pessoas" (CORNU, 1999, p. 383).

Com uma ideologia atrelada a um controle social perverso (MORAES, 2008), refratada na apologia ao uso da violência estatal, na anuência a julgamentos midiáticos de acusados, entre outras violações (VARJÃO, 2015), os noticiários criminais alinham-se, a princípio, a um jornalismo de convicção. Na prática profissional, porém, convicção e responsabilidade não são latentes aos gêneros. Por superar a lógica determinista de classificação entre diferentes produtos, um gênero é uma força, um modo de arranjar e rearranjar ideias, "meios e recursos expressivos, suficientemente estratificado numa cultura, de modo a garantir a comunicabilidade dos produtos e a continuidade dessa forma junto às comunidades futuras" (MACHADO, 2000, p. 68). No gênero criminal parece ainda haver ausência de atenção dos jornalistas sobre o papel político da profissão, embora haja entre eles percepções de que o nicho pertença ao que se convencionou chamar de quarto poder.

As críticas à metáfora são antigas. Cornu (1999, p. 384) a problematiza ao enfatizar os meios de comunicação "não estão munidos de nenhuma força, nem de uma qualquer autoridade geradora de obediência". Por outro lado, o jornalismo brasileiro é historicamente avaliado como um agente político-ideológico que funciona como uma espécie de vigia e de juiz do comportamento e do controle da agenda nacional. É nesse segundo campo que as narrativas criminais se apoiam para formar um estatuto de poder, vinculadas narrativamente a outras instituições, entre elas a família, o mundo do trabalho e a religião (ANDRÉ, 2018).

Por uma dimensão normativa, a responsabilidade política do jornalista só seria fiel à sua natureza caso fosse mantida fora do domínio político. Em outras palavras, elementos próprios do discurso político, como a persuasão, não devem integrar a essência do ofício, o que se entende por exterioridade (CORNU, 1999). Apesar de ser um serviço de bem público pautado pela controvérsia e, em paralelo, uma forma de organização empresarial, observa-se que a exterioridade política, como método de controle sobre o trabalho, proporcionaria ao jornalismo a possibilidade de desconstruir e recriar formas de narrar o mundo, mais voltadas ao 
debate público. Alvo de críticas, os noticiários criminais detêm propriedades para atender parte desses princípios, tema abordado na análise empírica.

\section{Entrevistados e procedimentos metodológicos}

Ao refletir sobre os aspectos morais difundidos pelo jornalismo criminal é possível ler esse fenômeno por um viés científico. A reflexão a respeito dos desafios prático-morais oferta subsídios para pensar sobre uma teoria moral em detrimento a uma avaliação filosófica especulativa da ética (SÁNCHEZ-VÁZQUEZ, 1987). Mais que criar juízos de valor acerca do objeto de estudo, uma abordagem científica auxilia na compreensão de fatos sociais mais complexos, como violações de direitos humanos ligadas mecanicamente ao gênero criminal.

Ainda que pesquisadores tenham como tarefa generalizar resultados, é preciso recusar a noção de que a metodologia seja um instrumento formal, rígido e neutro (BRAGA, 2011). Nesse sentido, este estudo qualitativo é um esforço para entender alguns dilemas do jornalismo criminal por uma perspectiva científica da ética. A problematização ocorre porque tais programas lidam com a noção de regionalização padronizada (HAMILTON, 2008), algo que sugere que os desafios enfrentados pelos entrevistados sejam, em maior ou menor grau, comuns a outros profissionais que cobrem crimes Brasil afora. Entre os principais produtos informativos da Record, o Balanço Geral possui versões em 20 estados e no Distrito Federal (RECORD, 2018). Com abrangência estadual, o Tribuna da Massa segue a lógica, já que as demais sucursais da Rede Massa no estado contêm versões próprias.

Dito isso, as entrevistas foram aplicadas na primeira semana de juIho de $2019^{2}$ com jornalistas do Tribuna da Massa ${ }^{3}$ e de Balanço Geral

\footnotetext{
20 questionário foi elaborado pelo autor e aplicado, sob supervisão, pelas acadêmicas Ana L. Z. Natal e Isabela Sebrão, participantes do projeto de pesquisa "Implicações da estigmatização e da invisibilidade social de personagens em noticiários criminais: um estudo sobre rotinas produtivas de jornalistas que cobrem crimes em Curitiba".

3 Veiculado entre segunda-feira e sexta-feira, das 11 h45 às 14h00, e aos sábados, das $12 \mathrm{~h} 30$ às 14h00, na Rede Massa, afiliada do SBT. É um programa que "traz notícias de Curitiba e região metropolitana, além dos acontecimentos mais relevantes do Paraná, que podem afetar o cotidiano da população" (MASSA, 2018).
} 
Curitiba ${ }^{4}$. Os encontros foram gravados, decupados e organizados em um arquivo com mais de 20 mil palavras. O questionário, formado por 28 perguntas, é dividido em quatro seções. A primeira tem como foco o levantamento de dados sobre a formação acadêmica e o histórico profissional para se compreender o perfil ${ }^{5}$ dos respondentes - os dados dela são descritos neste item. As demais partes são formadas por perguntas a respeito de percepções sobre gênero criminal, rotinas produtivas ${ }^{6}$ e dilemas éticos ${ }^{7}$, trabalhadas, respectivamente, nos três próximos tópicos.

Foram selecionados, a partir do critério de disponibilidade, cinco jornalistas graduados que atuam no Tribuna da Massa ou no Balanço Geral como repórteres. Com exceção de um deles, todos tiveram formação na iniciativa privada: o mais velho formou-se em 1999, o mais novo, em 2008. Os jornalistas, cuja média de idade é de 41 anos, já vivenciaram, no mínimo, dez anos de televisão - já a média de vínculo empregatício na empresa atual é de cinco anos e meio. Dois possuem formação lato sensu, relacionadas com a área da segurança pública ou com o meio TV. Apenas um atua em mais de uma atividade simultânea na área. Todos trabalharam em algum momento no rádio; dois exerceram também ocupação no meio impresso. Todos são repórteres, mas já ocuparam outras funções, como pauta e edição. O grupo é formado por jornalistas experientes, aspecto relevante para a compreensão sobre como esses profissionais encaram o ofício e problematizam os dilemas éticos.

As respostas abertas foram comparadas por meio de uma análise de conteúdo, método que consiste na sistematização dos dados a partir de inferências e, potencialmente, proporciona a identificação de construções simbólicas e estratégias narrativas em produtos e/ou em processos jornalísticos (HERSCOVITZ, 2010). Por possuir caráter heurístico,

\footnotetext{
4 Exibido entre segunda-feira e sábado, do meio-dia às 14h25, na RiCTV, afiliada da Record. É um noticiário que incentiva "soluções de problemas nas comunidades. O programa traz os fatos do dia e os assuntos informativos, através das matérias diferenciadas, investigativas e comentadas" (RICTV, 2018). 5 Naturalidade; Idade; Instituição onde se graduou; Se cursou pós-graduação; Quantos empregos tem; Vínculo empregatício; Em quais meios já atuou, tempo de vínculo e quais cargos já ocupou na emissora onde trabalha.

6 Identificação de casos que tenham marcado a trajetória profissional e/ou pessoal; rotina profissional; critérios de seleção para a midiatização de crimes; e percepções acerca das mudanças nas rotinas produtivas.

7 Avaliação sobre dilemas éticos que envolve o jornalismo criminal, relação com fontes oficiais, arrependimentos e méritos na escolha/enfoque das histórias narradas; respeito à presunção de inocência; contribuições do jornalismo criminal para a redução dos índices de violência; proximidade com o público como fórmula de sucesso editorial e, finalmente; se o profissional já sofreu ou sofre com algum tipo de ameaça pelo exercício da profissão.
} 
para cada um dos eixos da análise foram compiladas as respostas e realizada uma confrontação entre as falas. Metodologicamente, seguiu-se o princípio de que "o analista é como um arqueólogo. Trabalha com vestígios: os 'documentos' que pode descobrir ou suscitar. Mas os vestígios são a manifestação de estados, de dados e de fenômenos" (BARDIN, 2010, p. 41).

\section{Percepções sobre o jornalismo criminal}

Excetuados J2, que prestou serviço militar e se diz "fissurado em tiro", e J4, que começou a trabalhar ainda na adolescência cobrindo crimes no rádio, os demais entrevistados almejavam atuar com outros temas no início da carreira. A questão da escola que o jornalismo criminal representa e o anseio de encaixe no mercado são constantes nas respostas. $J 1$ destaca a experiência adquirida em um pequeno jornal como essencial para aprender o ofício a partir da cobertura de temas ligados à violência. Segundo ele, a flexibilidade para executar várias funções era especificidade dos veículos menores. Contudo, a imposição econômica passou a valer às grandes empresas, algo avaliado como compreensí$\mathrm{ve} /$ pelos entrevistados. A flexibilidade é relativa tanto às funções quanto aos temas. No primeiro caso há acúmulo de tarefas e a superação da carga horária de trabalho; no segundo, conforme os participantes, soma de experiências que enriquecem o repertório profissional.

A produção de matérias sobre variados temas foi elemento marcante nas carreiras de $\mathrm{J} 3$ e $\mathrm{J} 5$, e esse fator interferiu para que os dois fossem os mais críticos em relação à cobertura de crimes. Ambos afirmam que houve imposição para mudar a abordagem editorial nos veículos onde atuavam devido à queda na audiência. Único a asseverar que não gosta de trabalhar com na área, J5 avalia que em um mundo ideal os jornalistas precisariam cobrir vários temas, menos violência: "Mas o público quer ver isso. A RPC [afiliada da Rede Globo no Paraná] está se adaptando ao jornalismo popular hoje, que é o mundo cão, é o jornalismo policial. Não é o que eu quero, é o que o telespectador quer. Sou empregado" (J5).

O relato traz um aspecto usual nas falas: a terceirização da responsabilidade pela exibição de conteúdos sensacionalistas, processo pau- 
tado por uma idealização da audiência. Há uma percepção unânime entre os participantes sobre o uso do sensacionalismo como um recurso econômico. A justificativa de que o público gosta de sangue tem relação com a forma como esses jornalistas encaram a profissão - como questão empregatícia, de sobrevivência - e a violência é vista como uma estratégia de noticiabilidade. A vertente põe em xeque a exterioridade política desses jornalistas. Eles se sentem forçados a adotar estratégias de noticiabilidade envoltas por formas de persuasão que, por essência, divergem dos princípios deontológicos da área, o que não seria exclusivo ao nicho criminal, segundo as impressões do jornalista, algo que mostra a complexidade dos gêneros.

O ingresso a contragosto na função fez com $J 1$, J3 e $J 5$ tivessem percepções ruins em relação ao jornalismo criminal antes de exercê-lo. J3 diz que durante a universidade é comum se desenvolver "um senso crítico em relação a esse tipo de jornalismo", fator que o fazia ter "preconceito contra aquele tipo de jornalismo". Esse estigma o teria feito problematizar a atividade quando passou a cobrir segurança pública: "Comecei com a fórmula que entendo ser correta: não usar os termos que alguns repórteres que cobrem só policial usam, aquela coisa de exposição de uma pessoa que é presa, de cuidar com a imagem que ia fazer no local do crime, da exposição que eu ia ter com familiares de vítimas" (J3).

Mediado pelas rotinas, o dilema inicial fez com J1 e J3 passassem a gostar ou, no mínimo, a se acostumar com o ofício. Apropriando-se da argumentação de Cornu (1999), em ambos os casos, além das questões econômicas, por intuição de que o jornalismo criminal, a princípio um jornalismo de convicção, tem potencialidades para ser avaliado como um jornalismo de responsabilidade. "Quando você começa a cobrir essa editoria e a se identificar com ela, a perceber que você pode, além de fazer o seu trabalho, trabalhar pela transformação social, isso é muito legal" (J1). "Não vou dizer que comecei a me identificar com aquilo, mas comecei a ter uma boa relação com a chefia do programa. [...] Eu pensei: 'Acho que é possível fazer um policial com ética, com critério'” (J3).

Há uma divisão relativa às percepções sobre o jornalismo criminal - e isso interfere em como são problematizadas as questões deontológicas. Se no primeiro grupo há jornalistas que atuaram em outras editorias e funções $(J 1, J 3, J 5)$, no segundo há os que sempre cobriram crimes. 
J2 e J4 tiveram contato com o mundo criminal ou ostensivo antes da formação universitária (um como repórter de rádio desde a adolescência, outro após cinco anos na carreira militar seguido por um emprego como vigilante armado). Esse contexto contribui para que ambos sejam menos questionadores. Em que pese o fator econômico, a condição traz alentos, já que os jornalistas se formam cada vez mais jovens, o que significa que passam a ter mais oportunidades para refletir, sob o prisma deontológico, a respeito comportamentos prático-morais que envolvem as decisões corriqueiras desses produtos. Tal prerrogativa, longe de referendar uma polarização entre dois tipos de jornalismo, um bom e outro ruim, está ancorada na própria tendência de redução de imagens apelativas (AMARAL, 2011), embora seja inegável a permanência de densos juízos de valor, refratados, sobretudo, pelos âncoras.

Nessa linha, assim como J2, J4 cresceu assistindo a noticiários criminais, em um tempo em que "mostrava muito mais do que se mostra hoje". O hábito fez com que ele entendesse e naturalizasse como a cobertura de crimes é feita, algo que foi posto em prática quando iniciou no ofício. O nicho de atividade lhe ofereceu uma chance ainda aos 17 anos, fato que o fez "penalizar a adolescência" para trabalhar. "Ficava à noite em porta de delegacia, pegando ocorrências policiais. Fui aprendendo [... já na prática na rádio. Eu pegava tudo o que chegava no âmbito policial e fui me aperfeiçoando. Ganhei notoriedade com o passar do tempo [...]. Aí me formei pra vida" (J4).

Além dos discursos de intolerância e de apologia à violência, as narrativas criminais estão atreladas a questões familiares, religiosas e ao mundo do trabalho (ANDRÉ, 2018). Nesse aspecto, a ação de penalizar a adolescência por um emprego, ou de andar durante a madrugada por periferias, como reitera $\mathrm{J} 2$, aliada ao hábito de consumo de noticiários criminais durante parte da vida e à convivência com as formas estruturantes de violência, mostra indicativos de que esses jornalistas enfrentam desafios deontológicos para se manterem isentos ao domínio político (CORNU, 1999). Busca-se identificar se, como e por que o princípio da exterioridade da política é violado a partir das rotinas produtivas. 


\section{Impactos e reconfigurações das rotinas produtivas}

Indagado sobre momentos relevantes no jornalismo criminal, o grupo se dividiu: houve quem vinculasse a atividade a partir da força dos personagens envolvidos na história - frieza do agressor versus inocência da vítima - e os que destacaram a perspectiva de apuração jornalística e/ou os resultados da ação, abordagem que se vincula, sob o estatuto da ética, à exterioridade política. No primeiro grupo destacam-se casos de violência de natureza contra a pessoa e/ou dignidade sexual, em especial aqueles que envolvem categorias, inicialmente, desvinculadas do universo do crime: crianças (J2, J3, J4), idosos (J4) e mulheres (J3).

Embora $J 1$ admita ter tido vontade de agredir um homem acusado de abuso sexual contra quatro crianças durante uma entrevista, ele e J5 foram os únicos que não vincularam experiências profissionais a partir de histórias de vítimas e/ou agressores. Coincidência ou não, ambas as situações não estão ligadas diretamente a crimes de natureza contra a pessoa e contra a dignidade sexual, algo que, no mínimo, sugere que dentro do jornalismo criminal haja áreas mais sensíveis para a exteriorização política do que outras - e que, portanto, devam ser objeto de estudo permanente do campo da ética. Os dois episódios elencados por J5 foram relacionados a perseguições que sofreu de grupos policiais. Já J1 destacou uma série de reportagens que produziu a partir do uso de um perfil falso em uma rede social, quando conseguiu informações que culminaram na prisão de 13 pessoas integrantes de uma facção.

Os jornalistas dizem que as rotinas são intensas, sendo preciso cumprir mais demandas do que as previamente estabelecidas no acordo trabalhista. Parte desse pressuposto ocorre devido à precarização da profissão, mas a noção de romantização, na qual a vida pessoal é ajustada ao emprego, também é eminente. A idealização do jornalismo está presente nos critérios de noticiabilidade, desde materiais que geram comoção (J3, J4, J5) e que envolvem a lógica dramática da transmissão ao vivo $(J 1)$ até aqueles que se relacionam à cobertura de crimes contra a vida e contra a dignidade sexual (J2, J3, J4).

De acordo com os repórteres, a internet é estruturante quando se pensa na produção contemporânea em telejornalismo. Todos citam aspectos técnicos que auxiliam na apuração e circulação dos acontecimentos jornalísticos. Entretanto, o que se avalia a partir das respostas é 
que houve uma confluência entre a popularização da internet - sobretudo, a partir das redes sociais - com o próprio gênero criminal. Com o advento da web, o nicho ganhou relativo protagonismo sobre o modelo historicamente hegemônico de produção: o declínio do telejornalismo de bancada e a consequente valorização da linguagem mais informal (J1), a menor preocupação com a qualidade das imagens exibidas (J1, J2) e o agendamento de temas a partir das discussões na internet, independentemente da relevância do assunto (J3, J5), são apenas alguns exemplos.

Em outras palavras, a popularização da internet inegavelmente impactou a produção jornalística vigente, mas essa interferência se deu, sobretudo, no telejornalismo de referência. Significa dizer que várias das discussões sobre linguagens e formatos realizadas pelos telejornais contemporâneos já eram aceitas, em maior ou menor escala, pela estética do gênero criminal antes da internet: a impessoalidade do âncora como estratégia narrativa para se aproximar do público, herança oriunda dos programas de auditório, a exibição de imagens de perseguições policiais em plano-sequência e de cenas e pessoas envolvidas em crimes sem grandes preocupações técnicas e, finalmente, a disponibilidade para tratar com tempo de assuntos que não contenham interesse público. O fim do monopólio da produção e distribuição de informação, por outro lado, gerou uma série de tensões, e esse ponto fomenta desafios éticos que cerceiam a profissão.

\section{Entre a notícia e o público: dilemas éticos}

Das percepções sobre a área criminal e a compreensão das reconfigurações das rotinas, buscam-se entender dilemas éticos vividos. A síntese é que os participantes reconhecem as críticas, mas não se arrependem da forma como narraram ou produziram qualquer notícia - em especial, por conta da idealização de público. Mesmo reconhecendo as críticas, os jornalistas as rechaçam apontando as potencialidades dos noticiários (J1, J2, J4) e/ou avaliando que o jornalismo criminal deva ser objeto regular de crítica $(J 3, J 5)$.

Há quem considere que os profissionais são vistos com hipocrisia ou desprezo por parte da sociedade e, principalmente, da crítica. "Re- 
pórteres que cobrem a área policial não são bem vistos" (J2). Já o teor da resposta de $\mathrm{J} 4$ alerta para um desafio na formação: o envolvimento com as histórias. Conforme descrito, a natureza dos atos de violência interfere nos dilemas práticos-morais suscitados: "Falam que é sensacionalismo [exibir reportagens criminais]. É fácil criticar e difícil realmente não tratar de um drama de uma família com emoção" (J4). Já J1, usando um argumento que terceiriza ao público mais uma vez a responsabilidade pela midiatização dos crimes, diz que o sensacionalismo é um recurso que se relaciona mais a "quem recebe a informação do que a quem [a] conta" (J1).

$\mathrm{Na}$ outra ponta, $\mathrm{J} 3$ avalia que as críticas são justas, pois os programais criminais privilegiam situações dramáticas em detrimento ao interesse público, objeto do jornalismo sob o ponto de vista normativo. Se esses telejornais segmentados "erram muito" nas abordagens, por outro lado, a justificativa é, outra vez, o público. "Às vezes estou fazendo um assunto que acho importante, um serviço, mas, se ele não rende no Ibope, muda. Vai para outra coisa. Sei lá, às vezes, você está dando uma imagem que não vai acrescentar nada na sociedade, mas dá lbope" (J3). Ele acredita que esses produtos tenham como diferencial a capacidade de prestar serviços e de repercutir os fatos com abrangência. "Será que não é porque o jornalismo popular tem a capacidade de fazer uma matéria de cinco, nove, dez, quinze minutos que os casos de feminicídio começaram a ter mais mídia?" (J3). Para ele, a midiatização pode surtir efeitos benéficos: "Tenho que conversar com mãe, que vai chorar porque perdeu a filha, vou ter tocar na ferida da morte. Para ela não vai mudar nada. A filha já está morta. Mas é só com ela falando e sensibilizando para o tema é que talvez a gente consiga discutir e as autoridades se sensibilizem" (J3).

O envolvimento com os personagens é uma seara para uma discussão sobre fontes, que pode ser destrinchada em três pontos: consequência do acúmulo de atividades, presunção de inocência e, finalmente, os riscos que envolve a proximidade com fontes oficiais. Sobre o primeiro aspecto há consenso entre o grupo de que, dado o ritmo das produções, uma ou mais fontes deixem de ser ouvidas, fator que interfere no próprio princípio da presunção de inocência. "Você não tem tempo de fazer [a matéria] e escutar a família para ouvir o outro lado", explica J1 ao frisar o ritmo intenso de produção: "Às vezes não dá tempo. Você faz 
e já corre para lá. Aí acontece a possibilidade de erro. E de você ouvir só um lado, ou seja, quem falar primeiro" (J1).

Sobre presunção de inocência, as respostas fluem para duas linhas argumentativas que valorizam a necessidade de julgar (J1, J2, J4, J5). A primeira consiste em argumentos mais elementares e que vinculam o trabalho jornalístico às histórias de vítimas e/ou agressores: há na sociedade uma inversão de valores na qual "o bandido tem mais valor do que o cidadão" (J2); ou ainda, "[ele foi] pego em flagrante, filmado, muitas vezes, confessa, depois na visita do advogado, ele fala: 'Não, não fui eu...', mas tá filmado. [Não acusar é] só um termo legal, até a justiça definir o que a gente muitas vezes já sabia" (J4). Essa linha põe o jornalismo criminal como um dispositivo paralelo e disforme de justiça, encarada como objetivo específico da ação moral (FREITAG, 1992).

Já na segunda perspectiva há jornalistas que ratificam uma defesa constante nos depoimentos: o fato de que a profissão é aprendida no exercício diário. Apesar de ninguém ter se arrependido objetivamente pela forma como veiculou uma reportagem, a reviravolta em um escândalo de violência chamou a atenção de $J 1$ que, assim como os outros jornalistas que trabalharam no caso, veicularam a confissão de quatro pessoas apresentadas pela polícia como autoras de um crime de estupro de vulnerável seguido de homicídio. Dias depois veio a público que as declarações foram feitas mediante tortura.

J5 parece mais próximo do estatuto normativo do jornalismo de referência, seja para personagens, especialistas ou fontes oficiais: "Parto do princípio de que ninguém está falando a verdade" (J5). Quando o assunto são fontes oficiais, os jornalistas destacam a tentativa de distanciamento, mas há profissionais que, ainda que compartilhem esse preceito, não escondem ter amizades com policiais (J1, J2). Esse aspecto galvaniza a vulnerabilidade à exterioridade política, ao mesmo tempo em que restringe a prática do jornalismo criminal: os entrevistados avaliam que a atividade pode colaborar para a redução da criminalidade essencialmente a partir da identificação de criminosos. Por isso, há participantes que não enxergam qualquer relação entre a midiatização da violência e redução ou aumento dos índices e/ou que isso não deva ser uma preocupação do jornalista que cobre crime (J2, J3, J5). Embora todos afirmem de forma genérica que esses produtos sabem conversar com o público, nenhum cita as potencialidades narrativas. 


\section{Considerações finais}

O respeito pela pessoa é princípio fundamental para o exercício do jornalismo pautado pela responsabilidade. Essa condição pode gerar interpretações ambíguas, à medida que no estatuto deontológico valoriza-se a essência de que "a informação jornalística concerne uma verdade que interessa à sociedade civil e não à esfera privada" (CORNU, 1999, p. 403), mas questões de âmbito privado também interfiram em valores públicos (a violência doméstica é um exemplo). Ao procurar refletir por uma perspectiva ética com ênfase científica, procurou-se neste estudo, por meio de uma análise de conteúdo de entrevistas com cinco jornalistas que trabalham nos dois principais noticiários criminais de Curitiba, - Balanço Geral e o Tribuna da Massa, avaliar como dilemas éticos que envolvem a cobertura de crimes são naturalizados por profissionais frente a situações empíricas que exigem rápida solução.

Ao optarem por tratar da temática da violência a partir de estratégias narrativas de endereçamento ligadas a uma vertente de justiça e de verdade e, simultaneamente, ao instigarem ações que valorizam o controle social perverso, os programas funcionam como dispositivos de preconceitos e intolerância. Por outro lado, o estudo demonstra que parte dos produtores tem senso de responsabilidade sobre a profissão. As rotinas profissionais fazem com que os profissionais enxerguem potencialidades desses produtos como um jornalismo de responsabilidade, e não de convicção, mesmo que não tenham noções exatas sobre as potencialidades elencadas, sobretudo às narrativas. Isso, somada à popularização e ao êxito editorial do gênero, demonstra que há uma mudança estrutural na forma como se enxerga a política e, sobretudo, o próprio jornalismo.

Com a presente discussão, entende-se que deve haver cuidados nas escolas de jornalismo com a área criminal e, principalmente, com as percepções sobre o público, à medida que a terceirização da responsabilidade pela exibição de crimes ao público, tão presentes nas respostas, resume as potencialidades do jornalismo criminal à lógica econômica. Prova disso é que os profissionais acreditam que a redução da criminalidade essencialmente a partir da identificação de criminosos seja a contribuição mais eficaz desse jornalismo. 


\section{REFERÊNCIAS}

ANDRÉ, H. "Violência fascinante em vidas tão normais": relações de estigmatização e invisibilidade social na recepção de noticiários criminais. 2018. 528 f. Tese (Doutorado) - Programa de Pós-graduação em Jornalismo, Centro de Comunicação e Expressão, Universidade Federal de Santa Catarina, Florianópolis, 2018.

ANGRIMANI, D. Espreme que sai sangue: um estudo do sensacionalismo na imprensa. São Paulo: Summus Editorial, 1995.

AMARAL, M. F. Jornalismo popular. São Paulo: Contexto, 2011.

BARDIN, L. Análise de Conteúdo. Lisboa: Edições 70, 2010.

BRAGA, J. L. A prática da pesquisa em Comunicação: abordagem metodológica como tomada de decisões. E-Compós, Brasilia, v. 14, n. 1, p.1-33, jan. 2011.

BECKER, B. M. O sucesso da telenovela "Pantanal" e as novas formas de ficção televisiva. In: RIBEIRO, A. P. G.; SACRAMENTO, I.; ROXO, M. (org.). História da televisão no Brasil: do início aos dias de hoje. São Paulo: Contexto, 2010. pp. 239-257.

BRASIL. Daniel Cerqueira et al. Instituto de Pesquisa Econômica Aplicada (org.). Atlas da Violência. Rio de Janeiro: Ipea, 2018.

CORNU, D. Jornalismo e verdade: para uma ética da informação. Lisboa: Instituto Piaget, 1999.

FREITAG, B. Itinerários de Antígona: a questão da moralidade. São Paulo: Papirus, 1992.

HAMILTON, F. A. Monitorando telejornais: desafios e perspectivas. In: CHRISTOFOLETTI, R.; MOTTA, L. G. (org.). Observatórios de Mídia: olhares de cidadania. São Paulo: Paulus, 2008. pp. 95-114.

HERSCOVITZ, H. G. Análise de conteúdo em jornalismo. In: LAGO, C.; BENETTI, M. Metodologia de pesquisa em jornalismo. ed. 3. Petrópolis: Vozes, 2010. pp. 123-142.

MACHADO, A. A televisão levada a sério. 5. ed. São Paulo: Editora Senac, 2000.

MARTíN-BARBERO, J. Dos meios às mediações: Comunicação, cultura e hegemonia. ed. 7. Rio de Janeiro: Editora UFRJ, 2015.

MARTíN-BARBERO, J.; REY, G. Os exercícios do ver: hegemonia audiovisual e ficção televisiva. São Paulo: Senac, 2001.

MASSA, Rede. Tribuna da Massa. 2018. Disponível em: bit.ly/3bpkUTo. Acesso em: 8 jan. 2018.

MATHEUS, L. C. Narrativas do medo: o jornalismo de sensações além do sensacionalismo. Rio de Janeiro: Mauad X, 2011.

MORAES, P. R. B. Juventude, Medo e violência. In: GEDIEL, J. A.; MERCER, V. R. (org.). Violência, Paixão e Discursos: o avesso dos silêncios. Porto Alegre: CMC Editora, 2008.

OLIVEIRA, D. Jornalismo policial na televisão brasileira: gênero e modo de endereçamento. Vitória da Conquista: Edições UESB, 2014.

ORTIZ, R. A moderna tradição brasileira: cultura brasileira e indústria cultural. ed. 5. São Paulo: Brasiliense, 2001. 
RECORD. Programação local. 2018. Disponível em: bit.ly/2DsOmNN. Acesso em: 4 abr. 2018.

RICTV. Balanço Geral. 2018. Disponível em: bit.ly/3IQjfLo. Acesso em: 4 abr. 2018.

ROXO, M. A volta do "jornalismo cão" na TV. In: RIBEIRO, A. P. G.; SACRAMENTO, I.; ROXO, M. (org.). História da televisão no Brasil: do início aos dias de hoje. São Paulo: Contexto, 2010. pp. 177-195. SÁNCHEZ-VÁZQUEZ, A. Ética. ed. 10. Rio de Janeiro: Civilização Brasileira, 1987.

SILVA, G. Para pensar critérios de noticiabilidade. In: SILVA, G.; SILVA, M.; FERNANDES, M. Critérios de noticiabilidade: problemas conceituais e aplicações. Florianópolis: Insular, 2014. pp. 51-69.

VARJÃO, S. Violações de direitos na mídia brasileira: ferramenta prática para identificar violações de direitos no campo da comunicação de massa. Brasilia: ANDI, 2015.

Data do recebimento: 31 dezembro 2019

Data da aprovação: 07 outubro 2020 


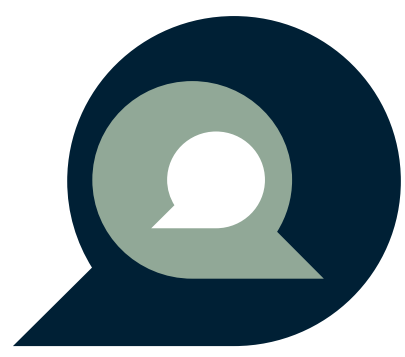

